\title{
Review Article \\ Transplacental RNAi: Deciphering Gene Function in the Postimplantation-Staged Embryo
}

\author{
K. Sue O'Shea, Lisa S. De Boer, Nicole A. Slawny, and Theresa E. Gratsch \\ Department of Cell and Developmental Biology, Medical School, University of Michigan, Ann Arbor, MI 48109-0616, USA
}

Received 1 February 2006; Revised 26 April 2006; Accepted 2 May 2006

\begin{abstract}
RNAi offers the opportunity to examine the role in postimplantation development of genes that cause preimplantation lethality and to create allelic series of targeted embryos. We have delivered constituitively expressed short hairpin (sh) RNAs to pregnant mice during the early postimplantation period of development and observed gene knockdown and defects that phenocopy the null embryo. We have silenced genes that have not yet been "knocked out" in the mouse (geminin and Wnt8b), those required during earlier cleavage stages of development (nanog), and genes required at implantation (Bmp4,Bmp7) singly and in combination $(B m p 4+B m p 7)$, and obtained unique phenotypes. We have also determined a role in postimplantation development of two transcripts identified in a differential display RT-PCR screen of genes induced in ES cells by noggin exposure, Aggf1 and an Est (GenBank AK008955). Systemic delivery of shRNAs provides a valuable approach to gene silencing in the embryo.
\end{abstract}

Copyright (c) 2006 K. Sue O’Shea et al. This is an open access article distributed under the Creative Commons Attribution License, which permits unrestricted use, distribution, and reproduction in any medium, provided the original work is properly cited.

\section{INTRODUCTION}

With the sequencing of the mouse genome [1], there has been tremendous interest in teasing out the function of "every" gene. In the mouse, gene targeting using homologous recombination in embryonic stem cells (ESC) has provided a unique opportunity to probe gene function in development [2], and a number of powerful techniques have been developed to target genes in temporal or tissue specific ways. Unfortunately, these are time consuming and often require the development of multiple strains of mice, which then must be mated to obtain the desired cell-type specific gene targeting. The recent application of posttranscriptional gene silencing using RNA interference (RNAi) to silence target genes has been an efficient way to study gene function initially in $\mathrm{C} \mathrm{el}$ egans and plants, later in mammalian cells in culture, and recently in embryos.

RNAi is a powerful alternative to traditional gene targeting using homologous recombination in ES cells, large scale mutagenesis, ribozymes, morpholinos, oligonucleotides, and so forth, for many reasons. Among these are simplicity in the design of the targeting construct, efficiency, and high throughput (reviewed in [3]). In addition, RNAi offers the ability to target specific exons/specific sequences within a gene [4], to study gene dosage phenotypes, to target multiple (redundant) genes, to target multiple members of a regulatory pathway, and to produce graded levels of knockdown analogous to allelic series, which is particularly useful in analyzing the effects of genes that have "threshold" effects rather than acting as binary on-off switches. In addition, RNAi may be particularly useful to avoid the confounding genetic background effects common to gene targeting using the limited number of "germ line" ESC lines, and finally, many other species (eg, rat) can be employed.

Relatively few studies have employed RNAi to study gene function in the developing embryo. RNAi has been electroporated $[5,6]$ or microinjected into oocytes or early zygotes [7-11], siRNA-transfected ES cells have been used to create germ line transgenic RNAi mice [12], or all ES embryos have been generated using tetraploid aggregation of RNAi-targeted ESC [13]. Delivery, particularly to postimplantation-staged embryos, continues to be a major limitation in the widespread application of this important technology.

Information regarding the prenatal delivery of plasmid DNA (pDNA) comes largely from the gene therapy field where in utero gene targeting/therapy has been proposed as a method to treat diseases that affect the developing embryo [14], which may ultimately be the most effective means to treat genetic defects. Various routes of pDNA delivery have been attempted for fetal "gene therapy" including direct injection of the fetus [15-17], injection into the placenta or umbilical cord $[18,19]$, injection into the amniotic cavity $[20,21]$, or the yolk sac [21], 
typically resulting in the limited transduction of the embryo.

Intravascular delivery of naked DNA is increasingly recognized as a preferred route to deliver nucleic acids to target tissues [22] because of its simplicity and effectiveness and because high levels of transgene expression can be achieved and sustained (eg, [23]). However, it has required either highpressure delivery to produce extravasation [24] or a tourniquet to keep the pDNA in place [23]. Tail vein injection has been employed to silence genes in neonatal [24], and adult mice [25-28]. Based on these reports, we have recently delivered shRNAs to pregnant mice and have observed gene silencing and additional six genes that play important roles in organogenesis of the early embryo.

\section{MATERIALS AND METHODS}

\section{Development of targeting constructs}

We developed a targeting construct that would allow us to deliver a single plasmid containing a small hairpin RNA (driven by the constitutively active $\mathrm{H} 1$ or U6 promoter) and a fluorochrome reporter driven by the CMV promoter (Figure 1). The vector backbone is the pCS2 plasmid (from David Turner), which contains two multiple cloning sites (MCS) for insertion of a DsRED and shRNA cassettes. A BamHI/XbaI fragment that contains the entire DsRed coding region was removed from pDsRed2-1 (Clontech) and ligated downstream of the CMV promoter in the first MCS. The H1 (GenBank AF191547) or the U6 (GenBank X06980) promoter was amplified in PCR with specific primers and SV129 mouse genomic DNA was then ligated into the second MCS. Genespecific shRNAs were designed to target Aggf1 (BC052410), Bmp4 (GenBank X56848), Bmp7 (NM007557), geminin (AF068780), nanog (AY278951), Wnt8b (NM011720), and Est1 (AK008955). Each shRNA is a ligated downstream of the $\mathrm{H} 1$ or U6 promoter to yield the final expression plasmid. All sequences are included in the supplemental data.

In addition to confirming that the plasmid reached the embryonic compartment (DsRed fluorescence), controls include empty plasmid (pRed) and hairpins containing three nucleotide substitutions (scrambled hairpins) that correspond to no known mRNA. Blast analysis confirms unique targeting of the hairpin and that no genes are targeted by the scrambled hairpin. We monitor target gene expression using PCR and at the protein level by Western blot or immunohistochemistry when an antibody is available. It is also important to monitor additional members of the signaling pathway, compensatory genes, irrelevant genes, and genes downstream of the target. We also monitor the interferon response gene Oas1 (GenBank AF466823) [29] to determine if our construct elicits a nonspecific response.

\section{Tail vein injections}

These are carried out in mice as we have described previously [30]. Pregnant females or neonates are placed in a conical tube (open at the tip for air flow). A small hole is also drilled into the cap to accommodate the tail. Mice are warmed for 5 minutes using a heat lamp and heating pad, then shRNA expression plasmids $(10 \mu \mathrm{g})$ diluted in Ringer's solution are injected into the tail vein. We use a $23-G$ needle and a volume of $200-300 \mu \mathrm{L}$ using a slow steady pressure, usually over 10 20 seconds for pregnant mice.

Because research in our laboratory has focused on the early postimplantation period of development, we have typically delivered targeting constructs at E6.5 and autopsied embryos $24 \mathrm{~h}$ to $72 \mathrm{~h}$ later. We have also carried out limited studies at midgestation when the placental barrier is most robust, as well as on E17.5 when the barrier thins and delivery should be more complete. We examine the extent of DsRed expression in all embryos using epifluorescence, followed by scanning electron microscopy (SEM), sectioning, immunohistochemistry, Western blotting, and/or PCR. DsRed is typically expressed throughout the early embryo, without a preference for a particular tissue type.

\section{Tissue analysis}

Pregnant females and neonatal mice are sacrificed by cervical dislocation followed by rapid dissection of embryos and tissues. Embryos are dissected from the decidua and images are captured using a Leitz-inverted fluorescence microscope to determine the extent of DsRed expression. Embryos are then either embedded in OCT for frozen sectioning or placed in Trizol for RNA/protein extraction. For SEM or whole mount immunohistochemistry (IHC), embryos are fixed in 1\% glutaraldehyde (SEM) or 2\% paraformaldehyde (IHC), then stored at $4^{\circ}$ prior to additional processing.

For scanning electron microscopy, embryos are dehydrated through graded alcohols, washed twice in hexamethyl disilazane (HMDS), oriented on SEM stubs, and sputtercoated with gold palladium. They are viewed and photographed using an Amray 1910 scanning electron microscope.

\section{Sectioning}

Unfixed sections are cut to determine the pattern of expression of DsRed and cell type specific markers using immunohistochemistry. Embryos are embedded in OCT and frozen in hexane cooled over anacetone-dry ice slurry. Sections are cut at $10 \mu \mathrm{m}$ using a microm cryostat and collected onto slides.

\section{Immunohistochemistry}

Frozen sections or entire embryos are fixed, blocked extensively, followed by primary antibody overnight. The geminin (sc-13015) and BMP4 (sc-6896) antibodies were obtained from Santa Cruz Biotechnology (Santa Cruz, Calif, USA); the nanog antibody from Kamiya Biomedical Company (Seattle, Wash, USA). Whole mount immunohistochemistry was carried out following [29]. Geminin and nanog primary antibodies were used at $1: 100$, BMP4 at $1: 50$. Secondary antibody-HRP $(1: 200$, Jackson Immunoresearch Laboratories, 


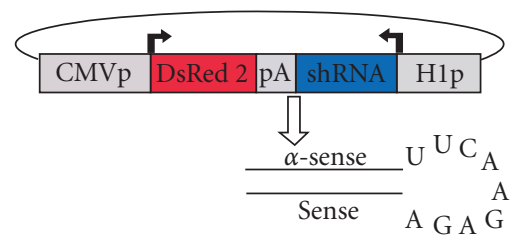

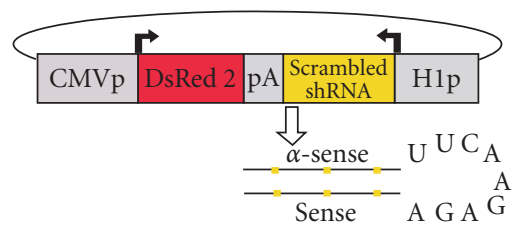

(a)

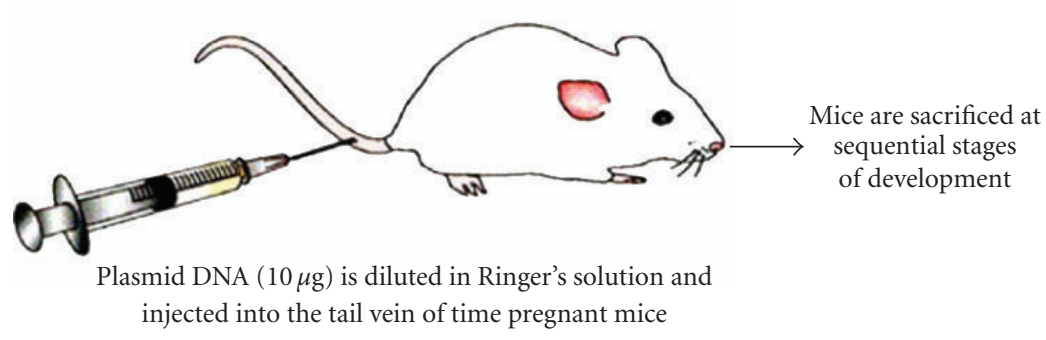

(b)

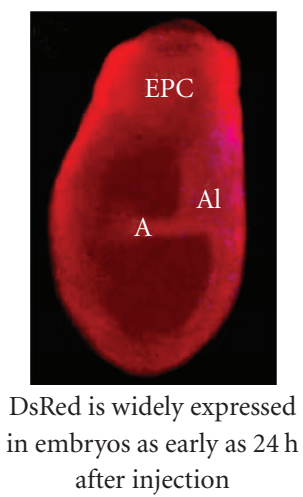

(c)

FIGURE 1: (a) shRNA expression plasmids were constructed using the pCS2 plasmid as the backbone. The DsRed 2.1 coding region was removed from the pDsRed2-1 vector (Clontech) and cloned downstream of the CMV promoter in the MCSI. The mouse H1 promoter (1040-1215 nt) of the RNAseP/PARP2 promoter, GenBank accession AF191547, was PCR-amplified from genomic DNA and cloned into MCSII. Gene-specific shRNAs (blue region) or scrambled shRNAs (yellow) are then ligated downstream of the H1 promoter. (b) Tail vein injections were carried out in pregnant mice as we have done previously (29). (c) Embryos are dissected from the uterus, and decidua and membranes are removed. Transmitted light and fluorescence images of embryos are captured using a Leitz-inverted fluorescence microscope to determine the extent of DsRed expression and to examine their morphology. A: amnion, Al: allantois, EPC: ectoplacental cone.

West Grove, Pa, USA). Images are captured using a Leitz Fluovert or DMIRB microscope then imported into Adobe Photoshop.

\section{$P C R$}

RNAs are extracted from embryos using the Trizol reagent (Invitrogen, Carlsbad, Calif, USA), quantified, and DNAsed. Prior to the reverse transcription (RT) reaction, RNA is subjected to 30 cycles of PCR with $\beta$-actin primers to verify that there is no genomic DNA present. RNAs $(1 \mu \mathrm{g})$ serve as templates in RT reactions with oligo-dT primers. General PCR conditions are $94^{\circ} / 3 \mathrm{~m}, 94^{\circ} / 1 \mathrm{~m}, 51-63^{\circ} / 1 \mathrm{~m}$, and $72^{\circ} / 2 \mathrm{~m}$ for $25-35$ cycles; however, parameters are optimized for each primer pair. The products are electrophoresed in $1.5 \%$ agarose gels in the presence of ethidium bromide, then images are scanned into the BioRad Gel Documentation system. For quantitative analysis of gene expression, real-time
PCR is performed using the Clonetech Qzyme system on a BioRad iCycler. Real-time PCR primers were designed and optimized by Clontech for use in multiplexed assays with $\beta$-actin serving as a reference gene. All reactions are performed in triplicate, and data are analyzed using the $2^{-\Delta \Delta}$ CT method.

\section{RESULTS}

We have delivered shRNA to more than 100 pregnant mice, and obtained both gene silencing and expression of the DsRed fluorochrome in embryonic tissues, persisting in postnatal mice. We have carried out a number of experiments to determine if implantation site is correlated with knockdown. In general, embryos implanted near the vagina exhibited greater knockdown than those near the ovaries. In most cases, there is knockdown and DsRed is expressed in embryos. Occasionally ( $\sim 5 \%$ of the injections), there is no 
transfection, likely because injection itself fails due to an insufficient amount of DNA entering the circulation.

\section{Geminin shRNA}

The geminin gene has been both down regulated and over expressed in Xenopus embryos, reducing or expanding the neural ectoderm fields, respectively [31]. Geminin is particularly interesting because, as suggested by its name, the protein has two functions: the C-terminus functions in cell cycle progression required for differentiation; the $\mathrm{N}$-terminal is involved in early neural differentiation [32]. Despite its provocative expression in the early neural ectoderm and demonstrated role in amphibian, Drosophila, and zebrafish development, there is not yet a knockout of geminin in the mouse.

When a shRNA targeted to geminin was delivered on E6.5, and embryos were examined one-three days later, we observed reductions in neural tissue, neural tube closure defects that typically affected the midbrain, and posterior neuropore. In early embryos, we observed abnormally expanded nodes and failure of closure of the primitive gut endoderm (Figure 2). When we examined geminin expression in whole mount immunohistochemistry, wild-type embryos were indistinguishable from control embryos exposed to the scrambled hairpin both in morphology and in the pattern of geminin protein expression in the newly induced neural ectoderm (Figures 2(a), 2(b)). Geminin was present at slightly higher levels in the anterior neural folds compared with the posterior region of early somite-staged control embryos (Figures 2(a), 2(b)). There was a slight geminin immunoreactivity in the neural ectoderm of some geminintargeted embryos (Figure 2(c)); while others expressed virtually no geminin protein (Figure $2(\mathrm{~d})$ ). When semiquantitative RT-PCR was carried out on RNA isolated from individual embryos from three litters, there was some variability in knockdown in the shRNA-exposed embryos, with two embryos expressing levels similar to control, others expressing intermediate, low, or no geminin mRNA (Figure 3).

Although geminin targeting in amphibian and Drosophila embryos has axis patterning and neural tissue consequences, there is no information on the early expression of geminin or targeted deletion of the geminin gene in the early mouse embryo. Since it is strongly induced by noggin, the observed neural, node, and endoderm abnormalities are likely due to the early expression of geminin in these tissues.

\section{Nanog shRNA exposure}

The nanog gene encodes a varient homeodomain protein originally identified in ES cells, where it is required to maintain pluripotency and inhibit lineage differentiation [33]. Targeted deletion in embryos is lethal before implantation [34], but additional evidence suggested that nanog is expressed in germ cells and somatic tissues later in development [35]; however, its role could not be assessed due to the early lethality of null embryos. To determine the role of nanog in later stages of development, we have exposed
21 litters of pregnant mice to shRNA-targeted to nanog via tail vein injection. We have observed widespread resorption of nanog-targeted embryos, and in other litters we have observed abnormalities of gastrulation and neurulation. Nanog knockdown embryos are characterized by axis abnormalities which are present in early somite embryos, considerably earlier in development than the turning process is initiated, endoderm overgrowth, and neural tube closure defects, particularly of the midbrain neural folds. Somite segmentation is also often abnormal, and we have observed abnormalities of cell migration through the primitive streak at gastrulation. Figures 4 and 9(b) illustrate some of these malformations.

In whole mount immunohistochemistry, nanog protein expression is significantly reduced, particularly in the primitive streak of embryos exposed to the nanog shRNA (37). To correlate phenotype and knockdown, we carried out quantitative PCR on RNA from individual nanog- targeted embryos from an entire litter. Silencing ranged from complete in three embryos to $60 \%$ of wild-type nanog levels in the least severely affected embryo. The presence of phenotypic abnormalities correlates strongly with the degree of knockdown, as illustrated in Figure 4 by the largely normal appearance of the embryo from lane 6, compared with the embryo from lane 7.

Somewhat surprisingly, two nanog-shRNA embryos expressed slightly elevated levels of the Oas1 gene (Figure 5, lane 15). Bmp4 expression was robust, however, suggesting that there had not been widespread silencing of nontargeted genes. Although it is widely employed to monitor off-target effects [36], Oas1 is expressed in muscle, brain, and connective tissue during development $[37,38]$. In addition, Oas1 plays a role in cell cycle progression [39], suggesting a need to monitor additional interferon targets in these studies.

\section{Targeting multiple genes: Bmp4, 7RNA interference}

Bmp4 has previously been shown to be required in the gastrulation-staged embryo, where it is important in mesoderm differentiation and organization of the primitive streak [40]. Later Bmp4 plays a role in determining the boundaries of the neural ectoderm and surface ectoderm [41], with particularly high levels of BMP4 associated with regions of epidermal ectoderm differentiation.

When a cocktail of shRNA targeted to Bmp4 (exons 2 and 3) was delivered on E6.75 of gestation to pregnant mice, we observed defects of neural tube closure, allantois development, and of heart and axial rotation (Figure 6(b)) in targeted embryos. The number of primordial germ cells identified by alkaline phosphatase staining was also strikingly reduced. RT-PCR analysis of RNA obtained from individual Bmp4 shRNA-exposed embryos from one entire litter identified only one embryo with any expression of $B m p 4$ (Figure 7).

Immunohistochemical localization of BMP4 protein was carried out on sections through shRNA- and pRed (plasmid lacking the hairpin) exposed embryos, and indicated significant depletion of BMP4 in targeted embryos [30]. We also have carried out Western blotting analysis of protein isolated 


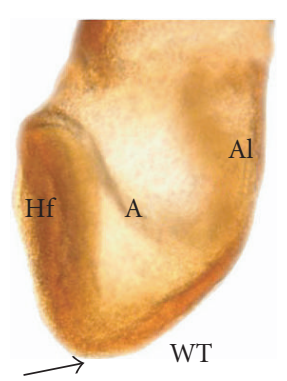

(a)

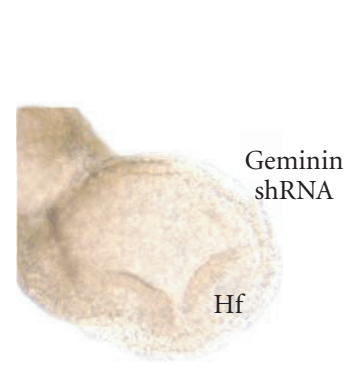

(d)

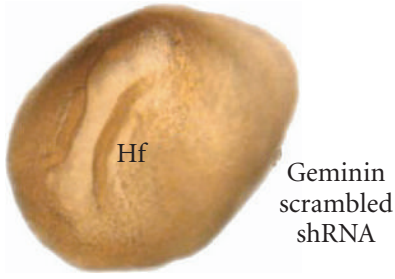

(b)

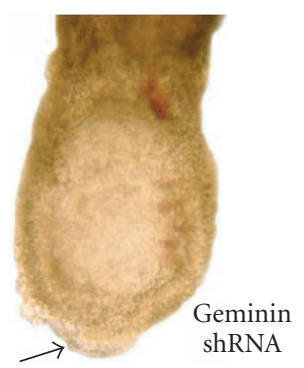

(e)

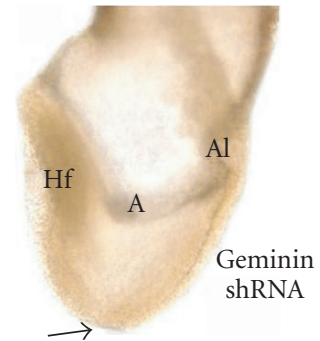

(c)

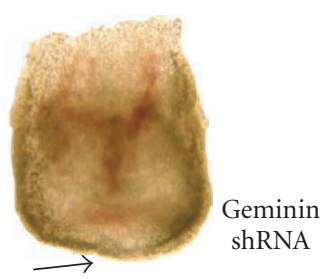

(f)

FIGURE 2: Immunohistochemical localization of geminin in control (a) and (b) embryos, and in embryos exposed on E6.5 to geminin shRNA ( $c$ and d). In control embryos, both wild type (a) and embryos exposed on E6.5 to a scrambled geminin hairpin construct (b), the expression of geminin protein was high in the neural ectoderm of the head folds, although geminin was also expressed in the posterior neural ectoderm as well (brown reaction product). There is a slight background staining of the allantois and membranes in all embryos (a)-(d). (c) and (d) Embryos were exposed to the shRNA-targeting geminin, examined and fixed on E7.5 of gestation, then immunohistochemistry to identify patterns of geminin protein expression was carried out as for (a) and (b) (secondary antibody-HRP). There is low-level geminin protein remaining in the neural ectoderm in embryo (c) less than that in embryo (d). (e) and (f) Transmitted light images of embryos exposed to the geminin shRNA on E6.5 and examined on E7.5. (e) Many targeted embryos exhibited axis defects, abnormal expansion of the node (arrow), and in later embryos, the endoderm of the gut tube often failed to close. (f) Occasionally, the embryonic axis appeared very flattened, and there was blood within the amniotic cavity. (a), (c), (e), and (f) are sideviews with anterior located toward the left. (b) is a dorso-lateral view, and (d) is a frontal (coronal) view. A: amnion, Al: allantois, Hf: head folds, WT: wild-type control embryo. Arrows indicate the node.

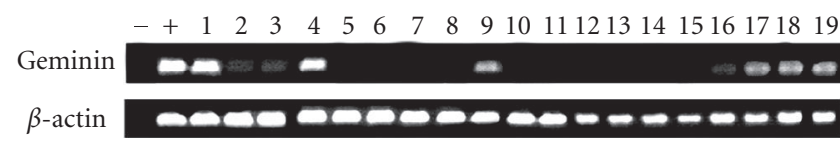

(a)

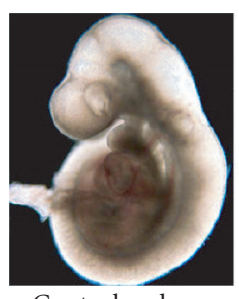

Control embryo

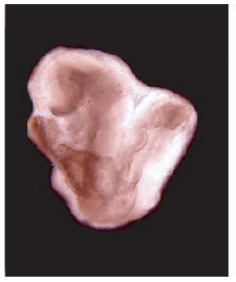

Embryo, lane 3

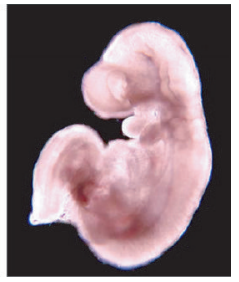

Embryo, lane 4

(b)

FIgURE 3: (a) Semiquantitative PCR to detect geminin expression in two entire litters of geminin shRNA- exposed embryos. Some embryos continue to express nearly normal levels of geminin (lanes 1,4$)$, while others express low $(2,3,16)$, intermediate (9, 17-19), or undetectable $(5-8,10-15)$ levels of geminin. The most advanced embryos consistently expressed the highest levels of geminin. Two entire litters of geminintargeted embryos were examined; $1-8$ and 9-19. - = no RT, + = E9 embryo RNA. (b) Sideview of control and embryos expressing varying levels of geminin.

from individual embryos exposed to $B m p 4$ shRNA, where there was a reduced expression of phospho-Smads $1 / 5 / 8$, which are phosphorylated in response to BMP4,7 signaling.

Conventional gene targeting of $B m p 4$ results in periimplantation lethality [40], while on a C57Bl/6 background embryos live until approximately 26 somite stage [41], and are characterized by axis elongation abnormalities. The results of the Bmp4 RNAi phenocopy many defects in the Bmp4 null embryos $[40,41]$ including anomalies of axis formation, primordial germ-cell differentiation, and neural tube closure 

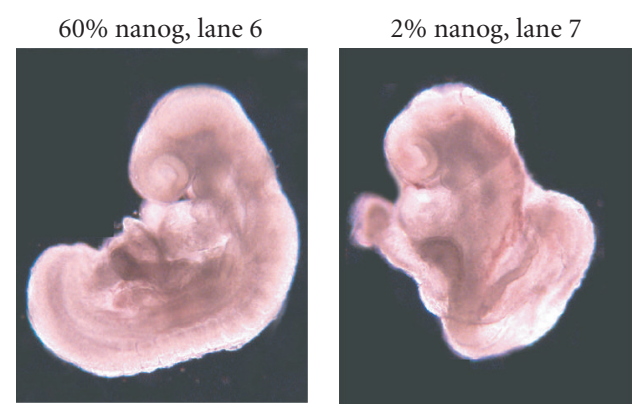

(a)

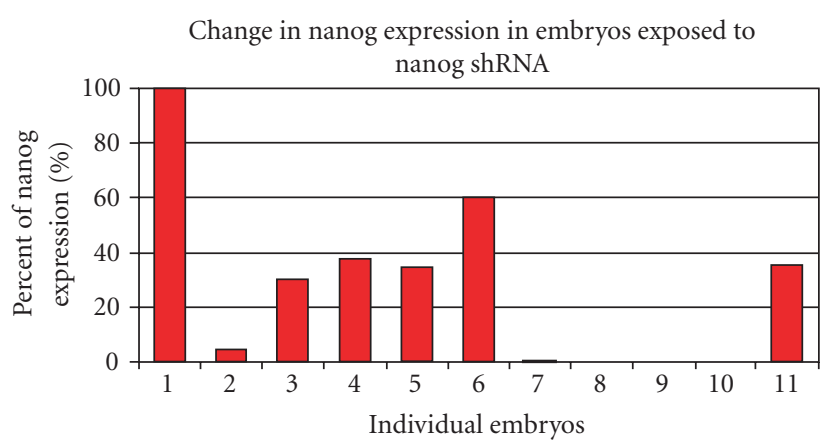

(b)

FIgURe 4: (a) Sideviews of two embryos exposed to nanog shRNA. Although the first embryo expressed $60 \%$ of wild-type levels of nanog mRNA, developmental defects are minor and include an axis abnormality and a flattened posterior neuropore. When nanog levels are reduced to $2 \%$ of wild type, embryos were more severely affected. The embryo in the right panel is characterized by defects of somite segmentation, neural tube closure, and abnormalities of endoderm differentiation. (b) Q-PCR analysis of nanog mRNA expression levels in individual embryos. Embryos were exposed on E6.5 to the nanog shRNA and examined on E9.0. cDNA from each embryo was run in triplicate in quantitative PCR with primers to both nanog and $\beta$-actin using the Clontech Qzyme system. Levels of $\beta$-actin and nanog expression from nanog shRNA-treated embryos (lanes 2-11) were compared to expression in a control embryo (lane 1). Nanog expression ranged from $0-60 \%$ of control levels. .

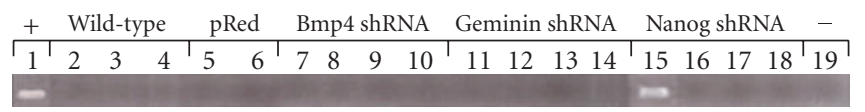

FIGURe 5: Oas1 PCR. Single embryo RT reactions were subjected to 40 cycles of PCR with primers for Oas1 mRNA (71). Mouse brain RT was used as a low-level expression positive control (+). Only 2 nanog shRNA embryos were positive for Oas1 expression (one shown, lane15). $=$ no cDNA control.

[30]. Many of these are also observed in embryos lacking Bmprla [42].

Because BMP proteins have overlapping functions in development, we examined the effects of knocking down multiple Bmps (Figure 6). We delivered a cocktail of shRNA targeted to $B m p 4+B m p 7$, as well as to $B m p 7$ alone. The $B m p 7$ shRNA embryos were the least severely affected (Figure 6(c)) with neural tube closure defects, while the $B m p 4+B m p 7$ shRNA embryos had widely expanded neural folds, defects of rotation, failure of development of posterior structures, and ventral body wall closure defects (Figure 6(d)), a more severe phenotype than either the Bmp4 shRNA or $B m p 7$ shRNA embryos, but strikingly similar to the caudal dysgenesis and the "massive brains" reported in Xenopus embryos following morpholino depletion of Bmp2, 4, and 7 [43].

\section{Durability of the RNAi}

To determine how long knockdown could be maintained, we carried out tail vein injection of shRNA targeted to Bmp4 on E6.5 and examined neonatal mice. On postnatal days $1-5$, neonates were characterized by cystic bladders, had rudimentary testes or ovaries, and were consistently growth retarded compared with mice exposed to the pRed control (Figure 8(a)). Expression of DsRed was maintained in many tissues in both the mother (including milk) and in the offspring (Figures 8(b), 8(c), 8(d),8(e), and 8(f)). There were also anomalies of the subventricular neural stem cell zone (SVZ; Figures 8(b), 8(c)) which depends on noggin-BMP4 signaling [44].

\section{Multiple targets, multiple phenotypes}

Although there are considerable data available regarding the role of secreted signaling molecules in the initial events of neural induction, very little is known regarding the genes that bridge the process of neural induction and neural differentiation. To identify novel genes that mark the earliest neural ectoderm, we carried out a differential-display RT-PCR screen of genes induced in mouse embryonic stem (ES) cells by noggin protein. From this screen, we selected several transcripts that were expressed in early embryos just after induction. Based on their expression profiles, we selected several candidates for RNAi silencing. Two of these had not previously been examined during development. During the course of our work, Aggf1 (angiogenic factor with Gpatch and FHA domains 1) was identified as an angiogenic factor mutated in human disease [45], but no information is available about its expression or role in development. Initial in situ hybridization studies indicated that Aggf1 is expressed at high levels in the distal epiblast, especially in the posterior epiblast on E7.5. At later stages it is expressed in the neural ectoderm. shRNA 


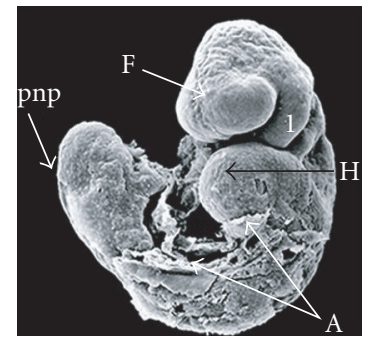

(a)

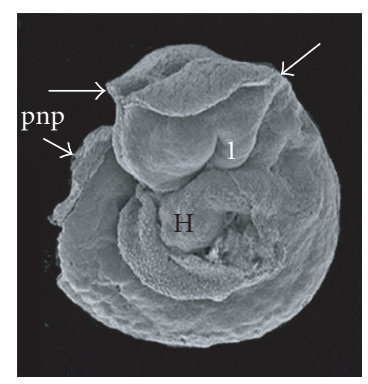

(c)

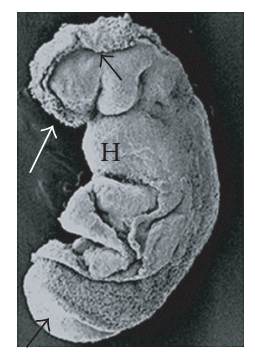

(b)

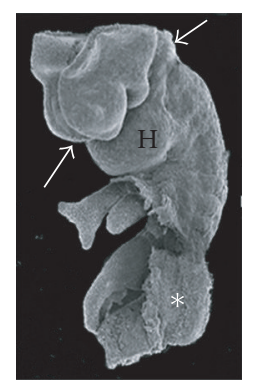

(d)
FIgURE 6: Effects of Bmp shRNA. (a) Scanning electron microscopy (SEM) view of a control embryo illustrating completed neural tube closure in the forebrain (F) region; the posterior neuropore (pnp) has not yet been closed. (b) Bmp4 shRNA-exposed embryo with widely open anterior neural folds (arrows) and posterior neuropore (lower black arrow). (c) SEM view of a Bmp7 shRNA-exposed embryo. Both the midbrain (arrows) and the posterior neuropore (pnp arrow) are widely open, but the body axis defects characteristic of $B m p 4$ shRNA and Bmp4 +7 shRNA embryos were not present. (d) Ventrolateral SEM view of a compound Bmp4 $+B m p 7$ shRNA embryo. The cephalic neural folds are unfused (arrows) and the posterior region is rudimentary $(*)$. 1: first branchial arch, A: amnion, F: forebrain, $\mathrm{H}$ : heart, pnp: posterior neuropore.

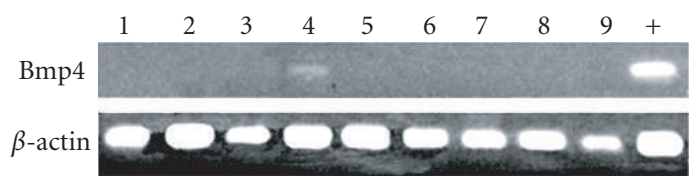

FIGURE 7: RT-PCR analysis of individual Bmp4 shRNA-exposed embryos from one entire litter. The positive control (+) is from an embryo exposed to pRed control vector alone. Pregnant dams were injected on E6.5 and RNA extracted from embryos on E9.0.

targeted to Aggf1 produced a lethal phenotype at E7.5. In these embryos, the ectoderm delaminated, and blood was often present within the amniotic cavity. Given its role in vessel formation, it is not surprising that we also observed implantation defects in shRNA-exposed embryos. Rare embryos that survived to E8.5 were characterized by focal hemorrhages and neural tube defects that affected midbrain and posterior neuropore (Figure 9(c)).
Est1 was identified twice in the differential display assay. Initial in situ hybridization localization studies indicate that it is expressed in the early epiblast, preconfiguring the primitive streak, in the node, later in the neural ectoderm. Targeting Est1 produced a severe neurulation phenotype, embryos with open neural folds, defects of embryonic rotation, and differentiation of posterior structures, reminiscent of genes involved in L-R axis patterning (Figure 9(d)).

A number of Wnt family members were also identified in this screen. Because $W n t 8 b$ had not previously been silenced, we delivered shRNA targeted to $W n t 8 b$ to pregnant dams on E6.75. Resulting embryos were characterized by axis elongation defects (Figure 9(f)). These embryos also had neural tube closure anomalies and defects in closure of the endoderm.

We have delivered shRNA targeted to Wnt8b, Bmp4, Bmp7, Bmp4 + Bmp7, geminin, nanog, and to two Ests identified in a differential display RT-PCR screen and observed specific targeting and unique phenotypes (Figure 9). These studies have also identified a previously unsuspected role for nanog in gastrulation and also in somite organization (Figures 4, 9(b)). Overall, we believe that these results are important and valid for a number of reasons. One, we have targeted multiple genes and observed unique phenotypes. These include Bmp4 (phenocopies the Bmp4 null embryos, as far as is possible to determine due to early lethality of the null embryos), Bmp7 alone, Bmp4 $+B m p 7$, Wnt8b, nanog, $A g g f 1$, and Est1. Two, in each case where an antibody is available to the protein (BMP4, nanog, geminin) or to the downstream signal transduction cascade (PhosphoSmad1, 5, 8), we have demonstrated knockdown in "individual" embryos. Three, in cases where an antibody is not available, we have demonstrated unique phenotypes and knockdown by PCR. Four, these data also demonstrate that we can knock down multiple targets, for example, $B m p 7$ and $B m p 4$, and identify an additive phenotype.

\section{DISCUSSION}

With genome-wide gene sequencing data now available, there is increased interest in systematically manipulating "all" the genes of the mouse to understand their roles in development and disease. Many new tools to manipulate gene function have been developed including ribozymes, microRNAs, DNAzymes, as well as a number of methods for posttranscriptional gene silencing such as morpholinos (review [46]), antisense oligos (review [47]), and RNAi (review [3]). RNAi is typically more robust than antisense oligos or morpholinos in embryos [48, 49], and morpholinos have the additional problem that the translational start site must be known, so uncharacterized genes (such as Ests) cannot be targeted.

RNAi may be particularly appropriate in targeting a developmental disease such as Down's syndrome/trisomy 21 once critical duplicated genes are identified, and may also be effective in targeting upstream pathways in metabolic disease to limit disease progression, or in silencing activating gene mutations, such as in the FGF receptor- 2 which produces 


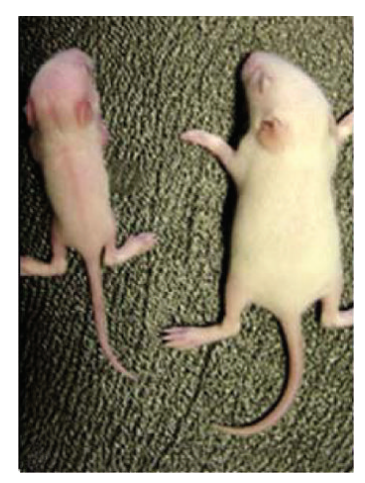

(a)

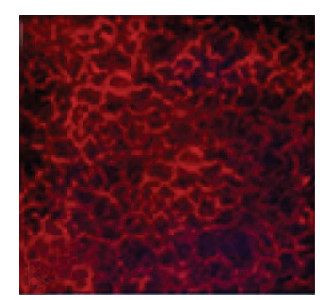

(d)

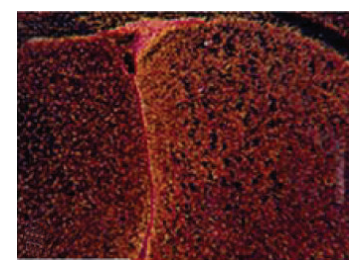

(b)

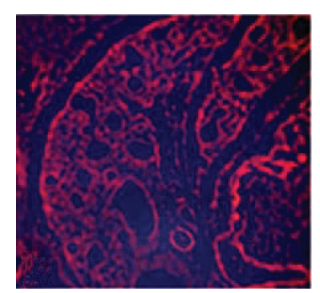

(e)

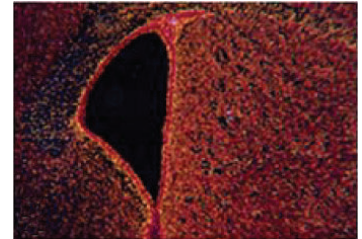

(c)

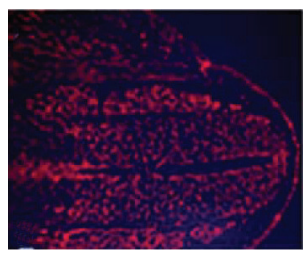

(f)

Figure 8: Longevity of the RNAi. (a) Day 10 neonatal mice (PN10) obtained from litters exposed on E6.5 to the Bmp4 shRNA (left) or to pRed (no hairpin plasmid) control (right). Bmp4 shRNA mice were consistently developmentally delayed and lacked testis or ovaries. (b) and (c) Coronal sections through the lateral ventricles of PN3 mice exposed on E17.5 to pRed control (b) or to Bmp4 shRNA (c). In addition to the obvious anomalies of the subventricular zone and ventricle, neural stem cells obtained from the Bmp4 shRNA mice fail to differentiate normally. (d)-(f) illustrate the persistent expression of DsRed in liver (d), lung (e), and spinal cord (f) in neonates exposed to Bmp4 shRNA on E6.5.

craniosynostosis [50]. Systemic delivery will also be applicable to diseases that affect tissues with open circulations, as well as diseases in which the blood brain barrier is opened such as Duschenne muscular dystrophy, certain brain tumors, in aging, and in multiple sclerosis (review [51]).

These studies have identified unsuspected roles in development for several genes. In the case of nanog, which in null embryos is lethal at early cleavage stages of development, we have identified a role in gastrulation, neurulation, and in endoderm differentiation. There is not a report of a knockout of the geminin gene in the mouse, and it will be of particular interest to study carefully the characteristics of the neural tissue in targeted embryos, as well as the characteristics of the node. Neither is there a published report of a Wnt8b knockout, but many of the defects observed in this study are similar to those present in other Wnt null embryos. For example, Wnt3a null embryos have similar severe posterior truncations [52]. The use of RNAi directed against individual Wnt mRNAs should allow rapid analysis of specific Wnt functions. In addition, since Wnts may compensate for each other, masking functions in single-gene knockouts, combinatorial Wnt RNAi should help elucidate overlapping relationships between the Wnts. Delivery of shRNA to pregnant dams has also provided an opportunity to rapidly determine if there was a role in early embryos for novel genes identified in a differential display RT-PCR screen. A role for Aggf1 in later aspects of vasculogenesis was described previously [45], and given its role in vessel development, it is not surprising that targeting $A g g f 1$ affected the implantation process.

The ability to target multiple genes with overlapping expression and function, as in the case of Bmp4/7 [53], is an important improvement over traditional knockouts in which mutations in multiple genes are obtained by breeding. In the future, it will be important to target multiple genes using a single plasmid containing multiple hairpins, rather than the cocktail we have employed to target Bmp4 and Bmp7.

To date, study of the placental transport of plasmid DNA has come largely from attempts to deliver pDNA for in utero gene therapy, which have produced conflicting results. Thus, when pDNA complexed with liposomes was delivered by intravenous injection of pregnant mice on E2.5, 5.5, 8.5, 11.5, or 14.5, no plasmid DNA was detected in fetuses exposed on E2.5 or E5.5, while embryonic expression peaked with delivery on E8.5, compared with E11.5 or E14.5. "All" embryos treated on E8.5 expressed the plasmid, with sustained expression at 40 days postinjection [54]. However, it has also been reported that DNA-liposome complexes were trapped in the visceral endoderm prior to placenta development on E11.5 [55]. Others have also reported hemodynamic transfer of genes to the fetal compartment, however. For example, 


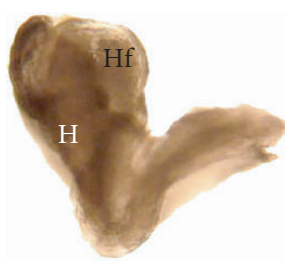

(a)

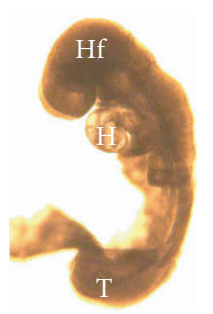

(e)

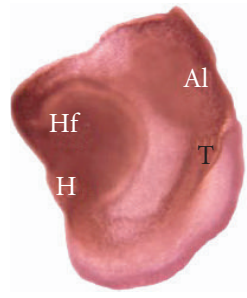

(b)

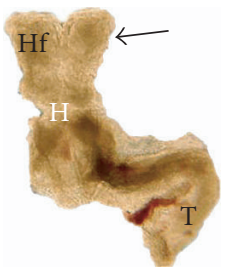

(c)

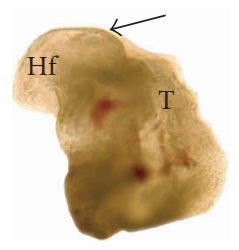

(d)

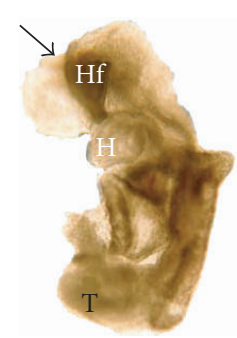

(f)

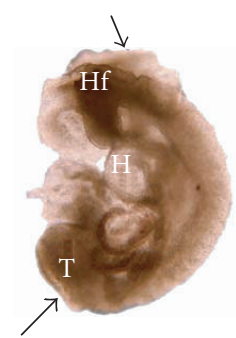

(g)

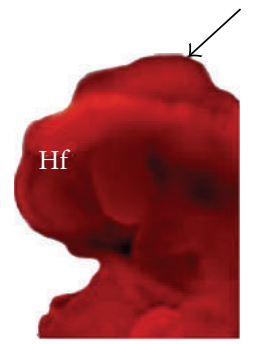

(h)

Figure 9: Control- and Gene-targeted embryos: nanog, geminin, Aggf1, and Est1. (a) Control embryo. Sideview of an embryo exposed to pRed plasmid (no hairpin) on E6.5 and examined on E8.5, illustrating the normal appearance of the head folds (Hf), somites, and unturned body axis. (b) Nanog shRNA. Embryo exposed on E6.5 to shRNA targeting nanog, illustrating the typical lack of development of the head folds (Hf) and posterior region in the tail bud (T). Somites have also failed to segregate normally. (c) and (d) We carried out a differential display RT-PCR screen of genes induced in D3 ESC by noggin exposure, then targeted two using tail vein injection of shRNAs. (c) Aggfl-targeted embryos failed to implant normally and the primitive ectoderm often delaminated into the amniotic cavity. Hemorrhages are present within the embryo; there are striking abnormalities of turning and posterior development in the rare embryo that survived to E8.5. (d) Est1-targeted embryo. There were anomalies of primitive streak organization in these embryos. They also often failed to turn to adopt the fetal position and exhibited abnormalities of the node. (e) pRed control. Sideview of an E8.5 pRed (no hairpin) control. This embryo is beginning the turning process, the body axis is elongated, neural folds are fused in the anterior (head fold, Hf) region, although the posterior neuropore remains open in the tail bud (T). (f) Wnt8b-targeted embryo illustrating the shortened axis and open neural folds typical of these embryos. (g) and (h) Geminin shRNA. An embryo exposed to geminin shRNA on E6.5 and examined on E8.5. There are very characteristic midbrain (upper arrows) and posterior neuropore (lower arrow in (g)) defects in these embryos, which exhibit widespread DsRed fluorescence $(\mathrm{H})$. All embryos are oriented with anterior toward the left. Al: allantois, H: heart, Hf: head folds, T: tail bud. Arrows indicate open neural folds.

intravenous delivery of plasmid DNA to pregnant mice on E9.5 successfully immunized the fetuses against HIV-1 and influenza [56]. We have avoided carriers since liposomes are often immunogenic, are generally less effective in serum, and can be toxic to both the embryo and the pregnant female [55].

Although we have obtained widespread expression of our construct, a number of improvements and alternative approaches can be considered. It would be possible to increase the amount of DNA injected, although $5 \mu \mathrm{g}$ plasmid DNA was optimal (saturating) and $>25 \mu \mathrm{g} /$ mouse was toxic $[57,58]$. Other studies have shown that transfection efficiency is not determined by volume or rate, but the amount of DNA delivered, with highest expression achieved with $1000 \mathrm{ng} / \mathrm{mouse}(23)$. Given the $\sim 1.6 \mathrm{~mL}$ blood volume of an $18 \mathrm{~g}$ mouse and observations that there is less degradation of pDNA in a larger volume of carrier [58], increasing the volume delivered would be an option. Rate of injection- -5 seconds is better than $30[24,58]$ —could also be considered, but very rapid injection can be lethal.
Despite careful breeding, the developmental stage of individual embryos at the time of exposure to shRNAs cannot be known precisely, and may account for some of the variability in our results. Alternatives include using exo-utero surgery of midgestation embryos with injection of shRNAs and electroporation [49]. For early postimplantation stages when exo-utero surgery is not applicable, whole embryo culture presents another option [59]. Better promoters and better control of CRE expression in the early embryonic compartment will allow the development of hybrid approaches to specifically, inducibly silence gene expression in a particular tissue/cell type (eg, 61). Interestingly, the oocyterestricted $\mathrm{ZP} 3$ promoter was recently employed to drive expression of dsRNA targeted to the Mos gene, recapitulating the null phenotype, with spontaneous parthenogenetic activation [60]. These and other recent investigations suggest that it will be possible to target RNAi to particular cells or tissues.

One drawback to tail vein injection is the loss of plasmid DNA to the female and unintended transfection of maternal 
TABLE 1

\begin{tabular}{|c|c|c|}
\hline Agof1 & tttacttcgaccatgacttgca & tttaTttcgCccatgacttgTa \\
\hline Aggil & gctcgtcctttctatcgaggc & gcGcgtcctGtctatcgagTc \\
\hline Bmp4 & $\begin{array}{l}\text { cagtccatgattcttggga } \\
\text { ccttcagaaaccggtcggc }\end{array}$ & $\begin{array}{l}\text { cagtcAatgaGtcttgTga } \\
\text { cAttcagaaTccggtAggc }\end{array}$ \\
\hline Bmp7 & $\begin{array}{l}\text { tccatctccgtagtatccg } \\
\text { ttcgacgacagctctaatg }\end{array}$ & $\begin{array}{l}\text { tccGtctccgCagtatTcg } \\
\text { ttcCacgaTagctctCatg }\end{array}$ \\
\hline Est1 & $\begin{array}{l}\text { cccgaacgatatttggtgtga } \\
\text { caagacgacgtgacaattcca }\end{array}$ & $\begin{array}{l}\text { ccGgaacgaGatttggtgtTa } \\
\text { caCgacgaTgtgacaattcTa }\end{array}$ \\
\hline Geminin & $\begin{array}{l}\text { tcatgtacacggectagcat } \\
\text { attcctgactatccggtga }\end{array}$ & $\begin{array}{l}\text { tAatgtacCcggectagAat } \\
\text { atCcctgactatAcggcga }\end{array}$ \\
\hline Nanog & $\begin{array}{l}\text { ttctgggaacgcctcatcaatgc } \\
\text { ggaagcagaagatgcggactgt }\end{array}$ & $\begin{array}{l}\text { ttcCgggaacAcctcatcaTt } \\
\text { ggaTgcagaCgatgTggactgt }\end{array}$ \\
\hline Wnt8b & $\begin{array}{l}\text { atgtacaccetgactagaaactgcagcct } \\
\text { gtccgctgcgagcagtgccgccgg }\end{array}$ & $\begin{array}{l}\text { aGgtacaccAtgactagatgcagAct } \\
\text { gGccgctAcgagTagtgccgccgA }\end{array}$ \\
\hline \multicolumn{3}{|c|}{ PCR Primers } \\
\hline Gene & Forward $5^{\prime}-3^{\prime}$ & Reverse $5^{\prime}-3^{\prime}$ \\
\hline Bmp4 & ctcccaagaatcatggactg & aaagcagagctctcactggt \\
\hline Geminin & gagaaaatgagttgccaaaagg & ccacagcttgaagtctgagatg \\
\hline Nanog & agggtctgctactgagatgctctg & atcttctgcttcctggcaag \\
\hline Oaslg & atggtagtatcaataagaagc & gcatagacagtgagtagctcc \\
\hline actin & ttgctgacaggatgcagaaggaga & actcctgcttgctgatccacatct \\
\hline
\end{tabular}

tissues. Since the liver has an expandable circulation and is easily transfected using intravenous delivery, it is important to monitor liver function in pregnant females and neonates. Obviously, when the targeted gene is important in maternal tissues, this is a larger concern that must be constantly monitored. Additional experiments might therefore include targeting of a nonessential protein such as EGFP in the GFPU mouse [61] which has no known downstream targets, nor have there been deleterious effects of EGFP cleavage products. It would be possible to mate hemizygous GFPU mice to determine if there are any deleterious effects that are transmitted to the nontargeted $+/+$ embryos. It would also be useful to target a gene expressed only in male embryos, so that female littermates would serve as a control for off-target and/or maternal effects.

It is impractical to carry out microarray analyses of individual, targeted embryos to determine specificity of targeting, although in previous studies when the targeting construct was specific, RNAi signatures were unique and highly specific for the target gene $[62,63]$. More detailed analysis can also be carried out to verify the presence of specific mRNA cleavage products using $5^{\prime}$ RACE, PCR to identify the cleavage fragments with sequencing [64]. It has generally been assumed that early development in the embryo is incapable of mounting a full interferon response [65], yet interferon responsive genes such as fragilis are expressed during very early postimplantation development [66]. Since Oas1 may have additional roles in development, monitoring other interferon-responsive genes would also be appropriate in these studies. Recent evidence also suggests that shRNA expression can competitively inhibit endogenous miRNA function via exportin 5 [67], although inclusion of scrambled hairpin constructs should control for this effect. Much remains to be understood about this technique, particularly regarding transport, uptake, and expression in the embryos and fetuses.

Since the first transgenic mouse was developed in 1980 by pronuclear injection of DNA [68], there have been major improvements to the technological base for mouse functional genomics, and RNAi promises to be a powerful new addition to that tool set.

\section{ACKNOWLEDGMENTS}

This work is supported by NIH Grants NS-048187, NS39438. The authors are grateful to JM Velkey and MH Morell for discussions and technical advice, to David Turner for the pCS2 plasmid, and to A George for unpublished data on primordial germ cell numbers.

\section{REFERENCES}

[1] Waterston RH, Lindblad-Toh K, Birney E, et al. Initial sequencing and comparative analysis of the mouse genome. $\mathrm{Na}$ ture. 2002;420(6915):520-562.

[2] Capecchi MR. Altering the genome by homologous recombination. Science. 1989;244(4910):1288-1292.

[3] Svoboda P. Long dsRNA and silent genes strike back: RNAi in mouse oocytes and early embryos. Cytogenetic and Genome Research. 2004;105(2-4):422-434. 
[4] Hemann MT, Fridman JS, Zilfou JT, et al. An epi-allelic series of p53 hypomorphs created by stable RNAi produces distinct tumor phenotypes in vivo. Nature Genetics. 2003;33(3):396400.

[5] Grabarek JB, Plusa B, Glover DM, Zernicka-Goetz M. Efficient delivery of dsRNA into zona-enclosed mouse oocytes and preimplantation embryos by electroporation. Genesis. 2002;32(4):269-276.

[6] Soares ML, Haraguchi S, Torres-Padilla ME, et al. Functional studies of signaling pathways in peri-implantation development of the mouse embryo by RNAi. BMC Developmental Biology. 2005;5:28. e-pub.

[7] Wianny F, Zernicka-Goetz M. Specific interference with gene function by double-stranded RNA in early mouse development. Nature Cell Biology. 2000;2(2):70-75.

[8] Hasuwa H, Kaseda K, Einarsdottir T, Okabe M. Small interfering RNA and gene silencing in transgenic mice and rats. FEBS Letters. 2002;532(1-2):227-230.

[9] Rubinson DA, Dillon CP, Kwiatkowski AV, et al. A lentivirusbased system to functionally silence genes in primary mammalian cells, stem cells and transgenic mice by RNA interference. Nature Genetics. 2003;33(3):401-406.

[10] Tiscornia G, Singer O, Ikawa M, Verma IM. A general method for gene knockdown in mice by using lentiviral vectors expressing small interfering RNA. Proceedings of the $\mathrm{Na}$ tional Academy of Sciences of the United States of America. 2003;100(4):1844-1848.

[11] Cao W, Hunter R, Strnatka D, McQueen CA, Erickson RP. DNA constructs designed to produce short hairpin, interfering RNAs in transgenic mice sometimes show early lethality and an interferon response. Journal of Applied Genetics. 2005;46(2):217-225.

[12] Carmell MA, Zhang L, Conklin DS, Hannon GJ, Rosenquist TA. Germline transmission of RNAi in mice. Nature Structural Biology. 2003;10(2):91-92.

[13] Kunath T, Gish G, Lickert H, Jones N, Pawson T, Rossant J. Transgenic RNA interference in ES cell-derived embryos recapitulates a genetic null phenotype. Nature Biotechnology. 2003;21(5):559-561.

[14] Coutelle C, Douar A-M, Colledge WH, Froster U. The challenge of fetal gene therapy. Nature Medicine. 1995;1(9):864866.

[15] Baldwin HS, Mickanin C, Buck C. Adenovirus-mediated gene transfer during initial organogenesis in the mammalian embryo is promoter-dependent and tissue-specific. Gene Therapy. 1997;4(11):1142-1149.

[16] Larson JE, Morrow SL, Happel L, Sharp JF, Cohen JC. Reversal of cystic fibrosis phenotype in mice by gene therapy in utero. Lancet. 1997;349(9052):619-620.

[17] Gaensler KML, Tu G, Bruch S, et al. Fetal gene transfer by transuterine injection of cationic liposome-DNA complexes. Nature Biotechnology. 1999;17(12):1188-1192.

[18] Papaioannou VE. In utero manipulation. In: Copp AJ, Cockroft DL, eds. Postimplantation Mammalian Embryos. Oxford, UK: IRL Press at Oxford University Press; 1990:61-80.

[19] Tūrkay A, Saunders TL, Kurachi K. Intrauterine gene transfer: gestational stage-specific gene delivery in mice. Gene Therapy. 1999;6(10):1685-1694.

[20] Douar A-M, Adebakin S, Themis M, Pavirani A, Cook T, Coutelle C. Foetal gene delivery in mice by intra-amniotic administration of retroviral producer cells and adenovirus. Gene Therapy. 1997;4(9):883-890.

[21] Schachtner SK, Buck CA, Bergelson JM, Baldwin HS. Temporally regulated expression patterns following in utero ade- novirus-mediated gene transfer. Gene Therapy. 1999;6(7): 1249-1257.

[22] Hodges BL, Scheule RK. Hydrodynamic delivery of DNA. Expert Opinion on Biological Therapy. 2003;3(6):911-918.

[23] Hagstrom JE, Hegge J, Zhang G, et al. A facile nonviral method for delivering genes and siRNAs to skeletal muscle of mammalian limbs. Molecular Therapy. 2004;10(2):386-398.

[24] Lewis DL, Hagstrom JE, Loomis AG, Wolff JA, Herweijer H. Efficient delivery of siRNA for inhibition of gene expression in postnatal mice. Nature Genetics. 2002;32(1):107-108.

[25] McCaffrey AP, Nakai H, Pandey K, et al. Inhibition of hepatitis B virus in mice by RNA interference. Nature Biotechnology. 2003;21(6):639-644.

[26] Song E, Lee S-K, Wang J, et al. RNA interference targeting Fas protects mice from fulminant hepatitis. Nature Medicine. 2003;9(3):347-351.

[27] Srensen DR, Leirdal M, Sioud M. Gene silencing by systemic delivery of synthetic siRNAs in adult mice. Journal of Molecular Biology. 2003;327(4):761-766.

[28] Soutschek J, Akinc A, Bramlage B, et al. Therapeutic silencing of an endogenous gene by systematic administration of modified siRNAs. Nature. 2004;432(7014):173-178.

[29] Dent JA, Polson AG, Klymkowsky MW. A whole-mount immunocytochemical analysis of the expression of the intermediate filament protein vimentin in Xenopus. Development. 1989;105(1):61-74.

[30] Gratsch TE, De Boer LS, O'Shea KS. RNA inhibition of BMP-4 gene expression in postimplantation mouse embryos. Genesis. 2003;37(1):12-17.

[31] Kroll KL, Salic AN, Evans LM, Kirschner MW. Geminin, a neuralizing molecule that demarcates the future neural plate at the onset of gastrulation. Development. 1998;125(16):32473258.

[32] Seo S, Herr A, Lim J-W, Richardson GA, Richardson H, Kroll KL. Geminin regulates neuronal differentiation by antagonizing Brg1 activity. Genes \& Development. 2005;19(14):17231734 .

[33] Mitsui K, Tokuzawa Y, Itoh H, et al. The homeoprotein nanog is required for maintenance of pluripotency in mouse epiblast and ES cells. Cell. 2003;113(5):631-642.

[34] Chambers I, Colby D, Robertson M, et al. Functional expression cloning of Nanog, a pluripotency sustaining factor in embryonic stem cells. Cell. 2003;113(5):643-655.

[35] Hart AH, Hartley L, Ibrahim M, Robb L. Identification, cloning and expression analysis of the pluripotency promoting nanog genes in mouse and human. Developmental Dynamics. 2004;230(1):187-198.

[36] Bridge AJ, Pebernard S, Ducraux A, Nicoulaz A-L, Iggo R. Induction of an interferon response by RNAi vectors in mammalian cells. Nature Genetics. 2003;34(3):263-264.

[37] Asada-Kubota M, Ueda T, Nakashima T, et al. Localization of $2^{\prime}, 5^{\prime}$-oligoadenylate synthetase and the enhancement of its activity with recombinant interferon- $\alpha \mathrm{A} / \mathrm{D}$ in the mouse brain. Anatomy and Embryology. 1997;195(3):251-257.

[38] Bisbal C, Silhol M, Laubenthal H, et al. The $2^{\prime}-5^{\prime}$ oligoadenylate/RNase L/RNase L inhibitor pathway regulates both MyoD mRNA stability and muscle cell differentiation. Molecular and Cellular Biology. 2000;20(14):4959-4969.

[39] Wells V, Mallucci L. Cell cycle regulation (G1) by autocrine interferon and dissociation between autocrine interferon and $2^{\prime}, 5^{\prime}$-oligoadenylate synthetase expression. Journal of Interferon Research. 1988;8(6):793-802.

[40] Winnier G, Blessing M, Labosky PA, Hogan BLM. Bone morphogenetic protein- 4 is required for mesoderm formation and 
patterning in the mouse. Genes and Development. 1995;9(17): 2105-2116.

[41] Lawson KA, Dunn NR, Roelen BAJ, et al. Bmp4 is required for the generation of primordial germ cells in the mouse embryo. Genes and Development. 1999;13(4):424-436.

[42] Mishina Y, Suzuki A, Ueno N, Behringer RR. Bmpr encodes a type I bone morphogenetic protein receptor that is essential for gastrulation during mouse embryogenesis. Genes and Development. 1995;9(24):3027-3037.

[43] Reversade B, Kuroda H, Lee H, Mays A, De Robertis EM. Depletion of Bmp2, Bmp4, Bmp7 and Spemann organizer signals induces massive brain formation in Xenopus embryos. Development. 2005;132(15):3381-3392.

[44] Lim DA, Tramontin AD, Trevejo JM, Herrera DG, GarciaVerdugo JM, Alvarez-Buylla A. Noggin antagonizes BMP signaling to create a niche for adult neurogenesis. Neuron. 2000;28(3):713-726.

[45] Tian X-L, Kadaba R, You S-A, et al. Identification of an angiogenic factor that when mutated causes susceptibility to Klippel-Trenaunay syndrome. Nature. 2004;427(6975):640645.

[46] Heasman J. Morpholino oligos: making sense of antisense? Developmental Biology. 2002;243(2):209-214.

[47] Lavery KS, King TH. Antisense and RNAi: powerful tools in drug target discovery and validation. Current Opinion in Drug Discovery and Development. 2003;6(4):561-569.

[48] Lefebvre C, Terret ME, Djiane A, Rassinier P, Maro B, Verlhac $\mathrm{M}-\mathrm{H}$. Meiotic spindle stability depends on MAPK-interacting and spindle-stabilizing protein (MISS), a new MAPK substrate. Journal of Cell Biology. 2002;157(4):603-613.

[49] Mellitzer G, Hallonet M, Chen L, Ang S-L. Spatial and temporal 'knock down' of gene expression by electroporation of double-stranded RNA and morpholinos into early postimplantation mouse embryos. Mechanisms of Development. 2002;118(1-2):57-63.

[50] Andersen J, Burns HD, Enriquez-Harris P, Wilkie AOM, Heath JK. Apert syndrome mutations in fibroblast growth factor receptor 2 exhibit increased affinity for FGF ligand. Human Molecular Genetics. 1998;7(9):1475-1483.

[51] Begley DJ. Delivery of therapeutic agents to the central nervous system: the problems and the possibilities. Pharmacology and Therapeutics. 2004;104(1):29-45.

[52] Liu P, Wakamiya M, Shea MJ, Albrecht U, Behringer RR, Bradley A. Requirement for Wnt3 in vertebrate axis formation. Nature Genetics. 1999;22(4):361-365.

[53] Dudley AT, Robertson EJ. Overlapping expression domains of bone morphogenetic protein family members potentially account for limited tissue defects in BMP7 deficient embryos. Developmental Dynamics. 1997;208(3):349-362.

[54] Tsukamoto M, Ochiya T, Yoshida S, Sugimura T, Terada M. Gene transfer and expression in progeny after intravenous DNA injection into pregnant mice. Nature Genetics. 1995;9(3):243-248.

[55] Kikuchi N, Nakamura S, Ohtsuka M, Kimura M, Sato M. Possible mechanism of gene transfer into early to midgestational mouse fetuses by tail vein injection. Gene Therapy. 2002;9(22):1529-1541.

[56] Okuda K, Xin K-Q, Haruki A, et al. Transplacental genetic immunization after intravenous delivery of plasmid DNA to pregnant mice. Journal of Immunology. 2001;167(9):54785484.

[57] Liu F, Qi H, Huang L, Liu D. Factors controlling the efficiency of cationic lipid-mediated transfection in vivo via intravenous administration. Gene Therapy. 1997;4(6):517-523.
[58] Liu F, Song YK, Liu D. Hydrodynamics-based transfection in animals by systemic administration of plasmid DNA. Gene Therapy. 1999;6(7):1258-1266.

[59] Calegari F, Marzesco A-M, Kittler R, Buchholz F, Huttner WB. Tissue-specific RNA interference in post-implantation mouse embryos using directional electroporation and whole embryo culture. Differentiation. 2004;72(2-3):92-102.

[60] Stein P, Svoboda P, Schultz RM. Transgenic RNAi in mouse oocytes: a simple and fast approach to study gene function. Developmental Biology. 2003;256(1):187-193.

[61] Hadjantonakis A-K, Gertsenstein M, Ikawa M, Okabe M, Nagy A. Generating green fluorescent mice by germline transmission of green fluorescent ES cells. Mechanisms of Development. 1998;76(1-2):79-90.

[62] Chi J-T, Chang HY, Wang NN, Chang DS, Dunphy N, Brown PO. Genomewide view of gene silencing by small interfering RNAs. Proceedings of the National Academy of Sciences of the United States of America. 2003;100(11):6343-6346.

[63] Semizarov D, Frost L, Sarthy A, Kroeger P, Halbert DN, Fesik SW. Specificity of short interfering RNA determined through gene expression signatures. Proceedings of the $\mathrm{Na}$ tional Academy of Sciences of the United States of America. 2003;100(11):6347-6352.

[64] Yekta S, Shih I-H, Bartel DP. MicroRNA-directed cleavage of HOXB8 mRNA. Science. 2004;304(5670):594-596.

[65] Barlow DP, Randle BJ, Burke DC. Interferon synthesis in the early post-implantation mouse embryo. Differentiation. 1984;27(3):229-235.

[66] Saitou M, Barton SC, Surani MA. A molecular programme for the specification of germ cell fate in mice. Nature. 2002; 418(6895):293-300.

[67] Yi R, Doehle BP, Qin Y, Macara IG, Cullen BR. Overexpression of Exportin 5 enhances RNA interference mediated by short hairpin RNAs and microRNAs. RNA. 2005;11(2):220-226.

[68] Gordon JW, Scangos GA, Plotkin DJ, Barbosa JA, Ruddle FH. Genetic transformation of mouse embryos by microinjection of purified DNA. Proceedings of the National Academy of Sciences of the United States of America. 1980;77(12 II):73807384 . 

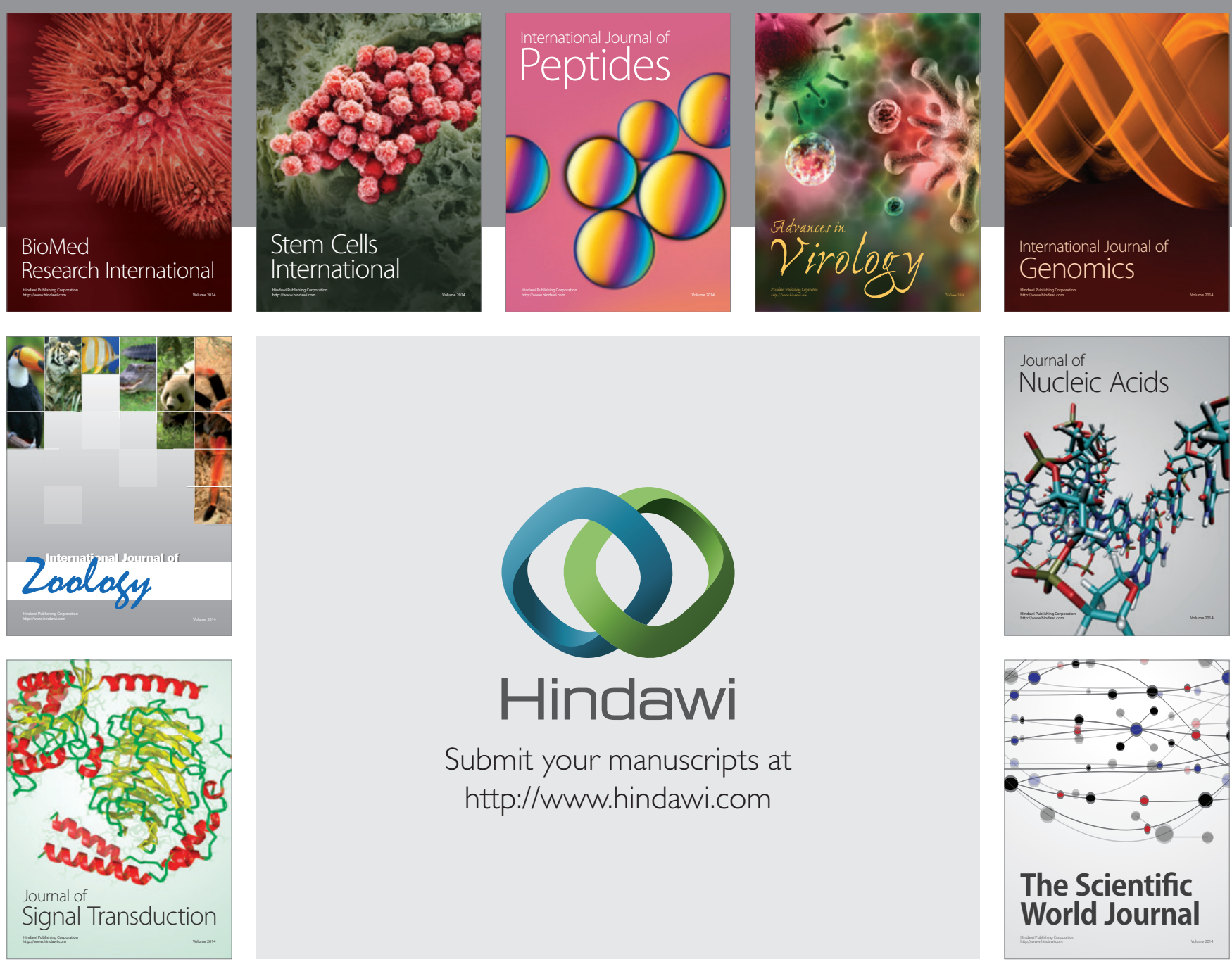

Submit your manuscripts at

http://www.hindawi.com
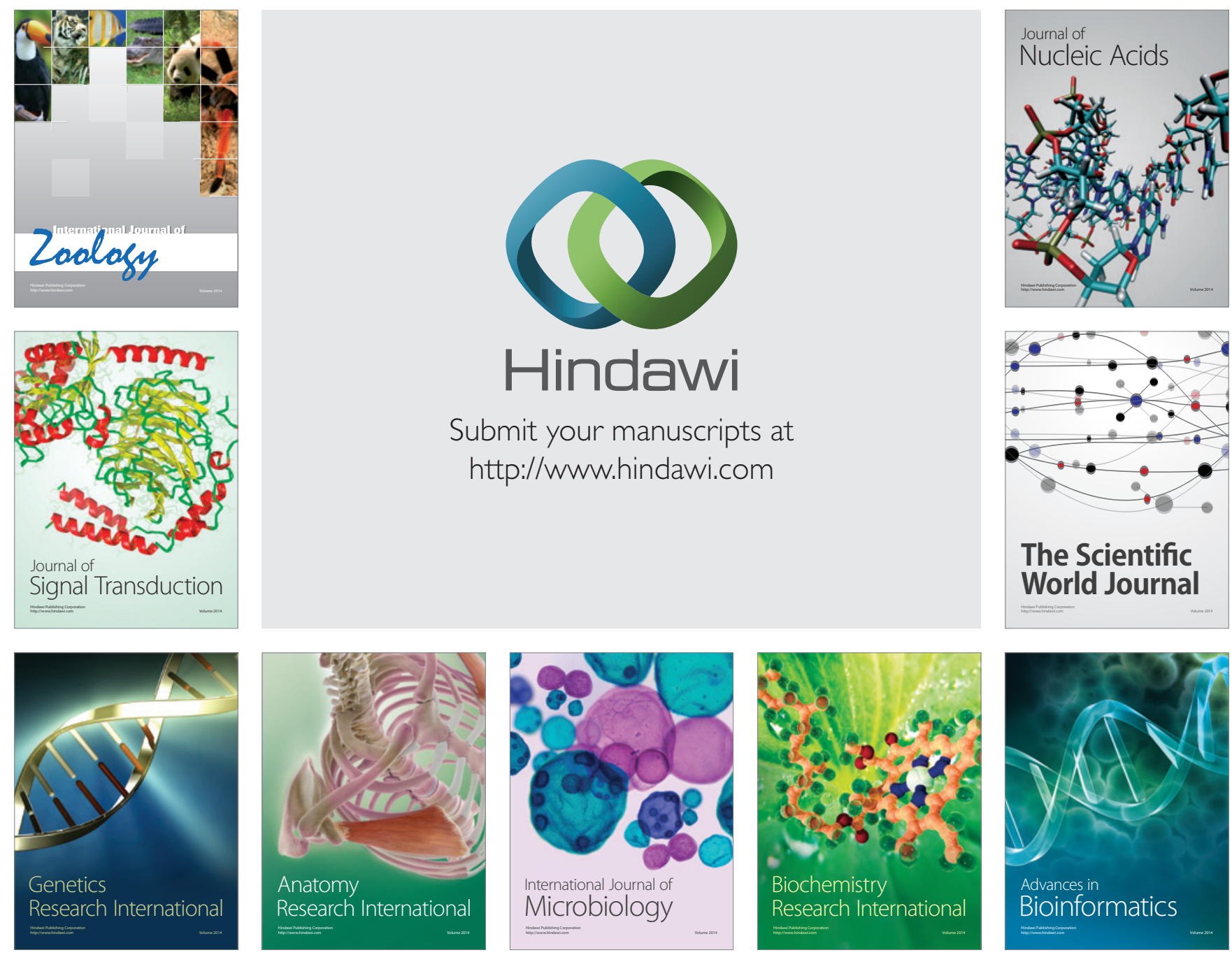

The Scientific World Journal
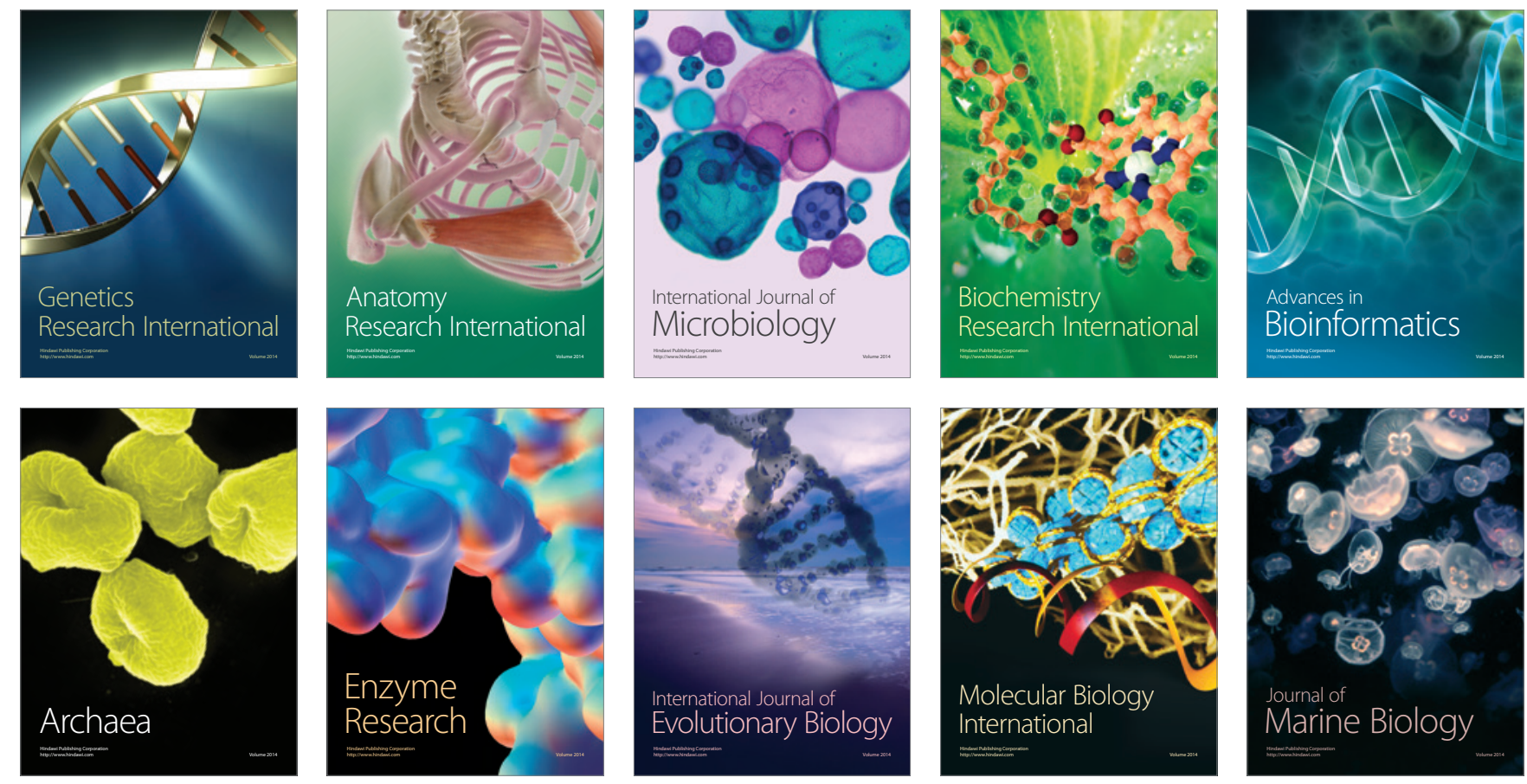